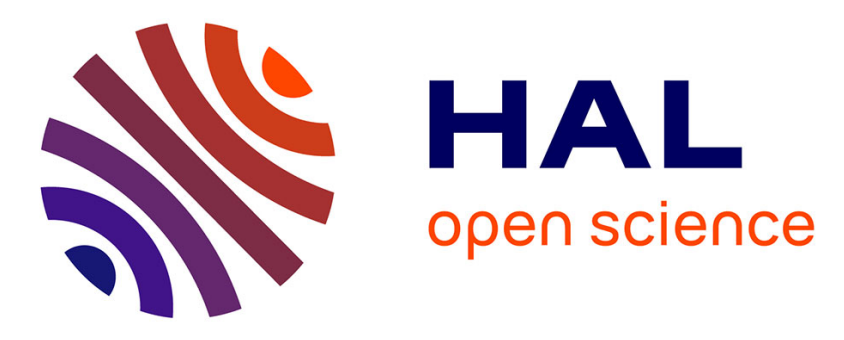

\title{
Oral sedation in dentistry: evaluation of professional practice of oral hydroxyzine in the University Hospital of Rennes, France
}

A Pouliquen, Emile Boyer, J-L Sixou, S B Fong, A Marie-Cousin, V Meuric

\section{To cite this version:}

A Pouliquen, Emile Boyer, J-L Sixou, S B Fong, A Marie-Cousin, et al.. Oral sedation in dentistry: evaluation of professional practice of oral hydroxyzine in the University Hospital of Rennes, France. European archives of paediatric dentistry: official journal of the European Academy of Paediatric Dentistry, 2021, 22 (5), pp.801-811. 10.1007/s40368-021-00620-7 . hal-03223955

\section{HAL Id: hal-03223955 \\ https://hal.science/hal-03223955}

Submitted on 20 Sep 2021

HAL is a multi-disciplinary open access archive for the deposit and dissemination of scientific research documents, whether they are published or not. The documents may come from teaching and research institutions in France or abroad, or from public or private research centers.
L'archive ouverte pluridisciplinaire HAL, est destinée au dépôt et à la diffusion de documents scientifiques de niveau recherche, publiés ou non, émanant des établissements d'enseignement et de recherche français ou étrangers, des laboratoires publics ou privés. 
Oral Sedation in Dentistry: Evaluation of Professional Practice of Oral Hydroxyzine in the University Hospital of Rennes, France.

Pouliquen $A^{1, *}$, Boyer $E^{1,2, *}$, Sixou $J-L^{1}$, Fong $S^{3}{ }^{3}$, Marie-Cousin $A^{1, \ddagger}$ and Meuric V. ${ }^{1,2, \ddagger}$

${ }^{1}$ Univ Rennes 1, CHU de Rennes, Paediatric Dentistry Department, Rennes, France.

2 INSERM, INRAE, Univ Rennes 1, CHU de Rennes, Nutrition Metabolisms and Cancer, Rennes, France.

${ }^{3}$ University of Rennes 1.

* and $\ddagger$ equal participation.

Short title: Oral hydroxyzine in dentistry

Abstract: 245 words.

Body of text (excluding Abstract, References, Figures and Tables): 3238 words.

Number of tables: 4 (+ 1 Supplementary Table).

Number of figures: 1.

CRediT author statement:

Alan Pouliquen: Investigation, Writing - Original Draft, Emile Boyer: Formal analysis, Investigation, Data Curation, Visualization, Writing - Review \& Editing, Jean-Louis Sixou: Investigation, Supervision, Writing - Review \& Editing, Shao Bing Fong: Writing - Review \& Editing, Alexia Marie-Cousin: Investigation, Writing - Review \& Editing, Project administration, Vincent Meuric: Investigation, Writing Review \& Editing, Project administration.

Corresponding author: E. Boyer, emile.boyer@univ-rennes1.fr

\section{Accepted manuscript}




\section{ABSTRACT}

\section{Purpose:}

Management of a child's anxiety early in their treatment is essential in dentistry. Sedative medications are used to overcome increased anxiety from previous appointments and to promote the cooperation of children during treatment. Hydroxyzine is currently prescribed to young patients as part of the first level of conscious sedation. The main objective was to evaluate the professional practice of oral hydroxyzine, when prescribed for children presenting anxiety during dental treatment procedure performed by students and senior practitioners.

\section{Methods:}

A retrospective study of dental records and questionnaires was conducted at the Dental Care Centre of the University Hospital of Rennes, France. Parameters related to the prescription of hydroxyzine in children were evaluated as potential predictors of the dental session success, with adjustments on potential confounders.

\section{Results:}

The therapeutic outcome was very encouraging with $78.3 \%$ of success during dental sessions under sedation with oral hydroxyzine. Anxiety levels before the dental procedure and the medication compliance of the child were the main predictors of success. On the other hand, lower age (<6 years-old) and longer treatments (such as pulpotomy) worsened the outcome.

\section{Conclusions:}

Careful analysis of the literature and results of this work showed the safety of hydroxyzine within the maximum dose authorized without adverse effects, compared to other molecules described and commonly used in dentistry. No adverse effects during dental procedure were noted. This allows for minimal sedation with efficiency for the great majority of pediatric treatment. This solution should be the first step in sedation to help practicing clinicians.

Keywords: Conscious sedation; Premedication; Treatment protocols; Hydroxyzine; Child behavior; Dental anxiety.

\section{Accepted manuscript}




\section{INTRODUCTION}

Dental treatment creates stress and anxiety and the relationship of trust between the patient and the practitioner is essential. This clinical reality is heightened when it comes to treating a child. The prevalence of anxious children ranges from $9 \%$ to $29 \%$ and decreasing with age, according to the literature (for review: Klingberg and Broberg 2007, Cianetti et al. 2017). Spotting and tracking anxiety, fear and stress are daily concerns for dentists. In pediatric dentistry, the management of anxiety is essential before treatment. The practitioner has different tools to limit and contain this stress, including positive communication, hypnosis, conscious parenteral and/or inhalation or orally administered sedation and finally general anesthesia.

Among the conscious medications, midazolam is a recommended drug which have proven its effectiveness despite associated adverse effects, according to a literature review based on the Cochrane meta-analysis (Ashley et al. 2018). As an alternative, hydroxyzine can be used in pediatric dentistry. Only one study using hydroxyzine as monotherapy has been reported in the literature reaching $100 \%$ of success at a dosage of $3 \mathrm{mg} \cdot \mathrm{Kg}^{-1}$ (Torres-Pérez et al. 2007). However, this protocol was not recommended by the authors as the behavior of the child was considered unreliable. Due to the large dosage and the small number of participants $(n=18)$ this effectiveness of hydroxyzine was not conclusive.

Oral hydroxyzine is usually prescribed to young patients as part of conscious sedation in the University Hospital. The main objective of this study was to evaluate the professional practice of oral hydroxyzine, for children presenting anxiety, during dental treatment procedure performed by students alongside senior practitioners (professors).

\section{Accepted manuscript}




\section{MATERIALS AND METHODS}

This work is an observational case series study that describes the use of oral hydroxyzine as a sedation protocol in children, prior to a single session of dental treatment. The method used was a retrospective survey of patients' dental records and questionnaires.

Patients were followed by students and senior dentists in the University Hospital. All selected patients were consecutive children and adolescents in need of oral conscious sedation without complementary $\mathrm{O}_{2} / \mathrm{N}_{2} \mathrm{O}$, with ASA PS $<2$ (The American Society of Anesthesiologists Physical Status). They had no disability or contraindication to oral hydroxyzine.

In accordance with the care protocol in the University Hospital, during their first consultation, the medical history was explored, the clinical and radiological examinations were carried out, and a motivation for oral hygiene was performed. No treatment was given during this initial contact, but the dental equipment and chair were shown, allowing the operator to assess the overall attitude of the child based on his/her compliance. The child's understanding and the objective modified Venham's Clinical Anxiety Rating Scale (VCARS) were reported (Venham et al. 1980). If a VCARS $\geq 3$ was reached during the first consultation, the patient was given a prescription for hydroxyzine ( 1 to $2 \mathrm{mg}^{\mathrm{kg}}{ }^{-1}$, accordingly to the recommendations for use of oral hydroxyzine), to be orally taken and administered by the parents 90 minutes before the next appointment. The dental treatment was then performed during a second visit.

Dental treatments included restorations of permanent or deciduous teeth, endodontic treatment of deciduous teeth (mainly pulpotomy), and extraction of permanent or deciduous teeth. Local anesthesia was administered using the electronically assisted injection systems SleeperOne $5^{\mathrm{TM}}$ or QuickSleeper $5^{\mathrm{TM}}$ devices (Dental $\mathrm{Hi} \mathrm{Tec}{ }^{\mathrm{TM}}$ ). The dental procedures were conducted by multiple operators, including students about to graduate ( $5^{\text {th }}$ and $6^{\text {th }}$ grade) and seniors.

From September 2019 to February 2020, a questionnaire was completed at the end of the second visit by the operators, which collated the following data:

- characteristics of the patient: age, gender, weight;

\section{Accepted manuscript}


- oral hydroxyzine prescription and compliance: dose, medication intake time, compliance to medication (did the child take all of his medication?), first exposure to oral hydroxyzine or not;

- patient's behavior: VCARS before, during and after the dental procedure;

- dental treatment: injection technique (infiltration or intra-osseous) and its completion, type of treatment planned for the visit (restorative, endodontic or extraction) and its achievement.

The main evaluation criteria and outcomes were the VCARS score during the dental procedure and the complete achievement of the treatment (therapeutic success). In the statistical analyses, factors considered as potential predictors were the pharmacological parameters: oral hydroxyzine dosage $\left(\mathrm{mg} \mathrm{kg}^{-1}\right)$, the interval between drug intake and the dental treatment $(\mathrm{min})$ and the compliance to medication. The factors considered as potential confounders were "age" and "gender" of the patient, "first exposure to oral hydroxyzine", "type of treatment planned", "injection technique used", "VCARS score before the dental procedure", "appointment time slot" and "highest grade operator that intervened during the procedure".

In some cases, the treatment was changed into atraumatic restorative treatment or in sealants. To avoid bias in the therapeutic success rate, they were classified as a therapeutic failure, since these treatments were alternative solutions when facing a non-cooperative patient.

The number of patients who received oral hydroxyzine prescription during the study period determined the sample size. During the study period, 2757 children were admitted in the University hospital, including 2280 (82.2\%) for treatment. Of these, $210(9.2 \%)$ benefited from conscious hydroxyzine sedation prescription. For the statistical analysis 184 questionnaires were selected; the remaining 26 were excluded due to completion errors (Figure 1).

The statistical analysis was carried out with the R kernel ( $v$ 3.5.0) in the RStudio environment ( $v$ 1.2.5033) ( $R$ Core Team 2018). Tables were generated with the 'qwraps2' and 'stargazer' packages, the figures with 'ggplot2' (DeWitt 2019; Marek 2018; Wickham 2016). Data are presented as percentages for qualitative variables, and as mean \pm standard deviation for quantitative variables. The results of the statistical tests were considered significant at $p<0.05$. The distribution of continuous

\section{Accepted manuscript}


variables was evaluated with the Shapiro-Wilk test which rejected the hypothesis of a normal distribution. The analysis of continuous variables was therefore carried out with the Mann-Whitney test. The analysis of the qualitative variables was carried out with the $\mathrm{X}^{2}$ test, or with the Fisher test when the conditions for the validity of $\mathrm{X}^{2}$ were not met. Odds-ratio (OR) are presented with 95\% confidence intervals $(95 \% \mathrm{Cl})$. The association between the success of the dental procedure and the characteristics related to the prescription and intake of oral hydroxyzine was evaluated using a multiple linear regression model (with the VCARS score during procedure as the dependent variable), and a logistic regression model (with the therapeutic success as the dependent variable). The explanatory variables were the factors considered as potential predictors or confounders previously described. Forty-eight patients had missing data (type of treatment planned and/or injection technique), and were not included in the regression models. The results presented indicate the coefficients (standard error) for each explanatory variable.

\section{Accepted manuscript}




\section{RESULTS}

The overall characteristics of the patient and pharmacological parameters for the second visit with treatment are presented in Table 1. Patients were mainly in early childhood ( $6.8 \pm 2.2$ years), with a male/female ratio of $56.5 \%$. The average hydroxyzine dosage was $1.63 \pm 0.39 \mathrm{mg}^{\mathrm{kg}}{ }^{-1}$. According to the self-reported medication intake time, hydroxyzine was orally administered $90 \pm 26$ min before dental procedure, which corresponded well to the prescription. The compliance to medication reached $85.9 \%(158 / 184)$.

In most cases, the dental procedure was successful at $78.3 \%$ (144/184 of therapeutic success) and no adverse effect during the procedure was observed. No significant difference was found in the characteristics of the patient according to the therapeutic outcome. Among the pharmacological parameters, the compliance to the medication was significantly associated with a therapeutic success $(p=0.01)$; logistic regression gave an $\mathrm{OR}=3.26,95 \% \mathrm{Cl} 1.36-7.83(p=0.008)$.

The data related to the second consultation are presented in Table 2. In general, we observed low VCARS scores in the population studied, with similar values before and after the procedure, and a peak during the procedure. Treatments were mainly restorative $(54.5 \%)$, on an anaesthetized tooth $(73.9 \%)$, and performed by $5^{\text {th }}$ grade students $(67.9 \%)$.

In case of therapeutic failure, patients were significantly more anxious, with VCARS scores almost three times higher than patients with successful treatment $(p<0.001)$. The type of treatment planned and the success of anesthesia differed according to the therapeutic outcome, with an increased proportion of endodontic treatment and failed anesthesia in the therapeutic failure group $(p=0.028$ and $p<0.001$, respectively).

Linear and logistic regression models were computed to assess the pharmacological parameters of oral hydroxyzine intake as predictors for the patient's anxiety and therapeutic success (Table 3).

In the multiple linear regression, the VCARS score during procedure was reduced by an average of 0.86 when the patient was compliant to medication $(p<0.05)$. One level of VCARS score before procedure increased on average by 0.66 the VCARS score during procedure $(p<0.0001)$. Patients requiring supplementary intervention

\section{Accepted manuscript}


by senior dentists presented a higher VCARS score, when compared to patients treated by $5^{\text {th }}$ grade students $(+1.40, p<0.01)$ or by $6^{\text {th }}$ grade students $(+1.19$, $p<0.05)$.

In the logistic regression, the association between the compliance to medication and a successful treatment was confirmed with the calculation of an adjusted $O R=6.28$, $95 \% \mathrm{Cl} 1.39-28.41(p<0.05)$. The successful achievement in endodontic treatment was lower than restorative procedures (OR $=0.07,95 \% \mathrm{Cl} 0.01-0.40, p<0.01$ ) or extraction $(\mathrm{OR}=0.17,95 \% \mathrm{Cl} 0.03-0.98, p<0.05)$. The VCARS score before the procedure was associated with the therapeutic outcome $(\mathrm{OR}=0.48,95 \% \mathrm{Cl} 0.29$ $0.79, p<0.01)$.

Finally, an analysis by age group was carried out to compare 3-5 to 6+ years-old children. A successful treatment was more frequently found in the oldest $(81 \%$ of treatment achieved versus $65 \%, p=0.04$ ) with lower VCARS score during dental procedure $(p=0.02)$ (Supplementary Table 1$)$.

\section{Accepted manuscript}




\section{DISCUSSION}

\section{Sedation protocols and adverse effects in the literature.}

Different protocols such as monotherapy or combination of drugs are used in dentistry to prevent anxiety. A summary of these protocols with doses, success and adverse effect is available in Table 4 . In our study, the dental treatment was successful in $78.3 \%$ of the dental sessions with the use of hydroxyzine as monotherapy.

The literature about midazolam used as monotherapy is heterogenous, in terms of therapeutic success (44-100\%), number of participants (12-57), and dosage form (enteral: $0.2-1 \mathrm{mg} \cdot \mathrm{kg}^{-1}$, intranasal: $0.2-0.5 \mathrm{mg} \cdot \mathrm{kg}^{-1}$, intramuscular: $0.2 \mathrm{mg} \cdot \mathrm{kg}^{-1}$ ). Adverse effects such as nausea, vomiting and oxygen desaturation were reported and the higher the dosage increased the more frequent they were noticed (Day et al. 2006; al-Rakaf et al. 2001; Sado-Filho et al. 2019; Somri et al. 2012). Studies reporting $\mathrm{N}_{2} \mathrm{O}$ as monotherapy revealed that dental treatment was completed in $52 \%$ of cases at a concentration of $40 \%$ (Lahoud and Averley 2002) and up to $85 \%$ with an equimolar mixture (Nelson et al. 2017) with no adverse effect reported. In two studies reporting the use of hydroxyzine in combination with midazolam, $69 \%$ and $100 \%$ of dental treatments completed were found with a greater success with the highest dosage but the number of participants were low ( $n=10$ and 18 respectively) (Ghajari et al. 2016; Torres-Pérez et al. 2007). When combined with an opioid (Meperidine), success increased up to $95 \%$ but adverse effects such as nausea, vomiting and severe desaturation (90\%) were described (Lenahan et al. 2015). Hydroxyzine combined with $\mathrm{N}_{2} \mathrm{O}$ allowed the treatment in $66 \%$ of cases $(n=15)$ according to Baygin (Baygin et al. 2010). This study also showed the same success rate with a combination of ketamine / midazolam / $\mathrm{N}_{2} \mathrm{O}$ or $\mathrm{N}_{2} \mathrm{O}$ used alone but with adverse effects such as enuresis, bronchospasm, hypersalivation, hallucination, epistaxis and earache. Finally, other associations with or without the integration of hydroxyzine in the protocol showed success rates ranging from 66 to $100 \%$ with midazolam and ketamine (Baygin et al. 2010; Sado-Filho et al. 2019), 87\% with midazolam / hydroxyzine / meperidine / $\mathrm{N}_{2} \mathrm{O}$ (Lane et al. 2015), 91 to $100 \%$ with midazolam / $\mathrm{N}_{2} \mathrm{O}$ (Lam et al. 2005).

These comparisons highlight greater success in treatments compared with our sedation protocol, but they are associated with multiple adverse effects. Nausea,

\section{Accepted manuscript}


vomiting, drowsiness and oxygen desaturation are also reported in studies that have the pharmacological objective of looking for adverse effects (Huang and Tanbonliong 2015; Ritwik et al. 2013). An American case report analysis looking at severe neurological damage and death showed that combinations of more than 3 drugs, overdose, and lack of training are the causes of these accidents. In addition, dentists are the most represented practitioners because they have been known to use combinations of 3 or more drugs (Coté et al. 2000). For example, Shapira et al. used sedation combining $3.7 \mathrm{mg} \cdot \mathrm{Kg}^{-1}$ of hydroxyzine, $0.6 \mathrm{mg} \cdot \mathrm{Kg}^{-1}$ of midazolam and $\mathrm{N}_{2} \mathrm{O}$ (Shapira et al. 2004). To secure sedation, in 2006, the AAP (American Academy of Pediatrics) and the AAPD (American Academy of Pediatric Dentistry) published guidelines that define 3 levels: minimal, moderate or deep. They also underline the training required and the necessary equipment (Pediatrics et al. 2006). Then, in 2016, the ADA (American Dental Association) published a similar procedure for performing sedation or general anesthesia by dentists (Clough et al. 2016). Finally, Clough et al. showed that dentists do not use the ASA PS score enough for sedation.

\section{Safety of hydroxyzine}

During this practice evaluation, no adverse effects were reported by the children undergoing treatment, parents or practitioners during the dental procedure. Hydroxyzine prescriptions comply with the maximum dosage indicated in the monograph (Prescribers' digital reference 2020). There was no overdose or inappropriate use of this medication. The use of an antihistamine in a pediatric dentistry is justified by its pharmacological safety profile (Motola et al. 2017). However, a 1994 study showed that second generation antihistamines, and to a lesser extent hydroxyzine, which is first generation, could induce QT interval prolongation (Smith 1994). In 2014, a study showed that this lengthening is mainly the consequence of action on the cardiac potassium channels without implicating hydroxyzine (Olasińska-Wiśniewska et al. 2014). In 2017, a pharmacovigilance review on hydroxyzine gave an account of 59 cases of long QT between 1955 and 2016 and demonstrated that it only appeared if there was a pre-existing heart disorder, an overdose or a genetic anomaly of the modulation of the cardiac ion channels (Schlit et al. 2017). Finally, a case report described the appearance of ventricular tachycardia in a 9-year-old girl following anti-pruritus treatment without a blood test link being able to confirm it (Wong and Rasool 2004).

\section{Accepted manuscript}




\section{Compliance of the patient}

The pre-operative behavior of the child is decisive because the compliance to medication (hydroxyzine fully taken) indicates a drop in the VCARS score during the treatment and is correlated with the success of the treatment $(\mathrm{OR}=3.26$ and adjusted OR $=6.28)$. A similar result was found by Lenahan et al. with $85 \%$ success when drugs were taken on a voluntary basis. However, this result dropped to $59 \%$ when taken involuntarily (Lenahan et al. 2015), as in our study which stands at $57 \%$. The lower the VCARS score before the treatment, the easier the treatment to be performed. Therefore, the evaluation of the child's behavior during the first consultation is essential because the practitioner can detect an impulsive character which is predictive of difficult treatment (Lane et al. 2015) or the child's ability to control himself (Nelson et al. 2017). The use of tell play do during this consultation reduces anxiety and therefore the child's VCARS score (Vishwakarma et al. 2017), and this technique is used within the University hospital. The use of this behavioral approach by students during the first consultation may be worth evaluating in order to optimize stress management in young patients.

\section{Age of patients and operators}

This study showed that younger children are more difficult to treat, with a higher VCARS score and a less successful treatment as described by Lenahan et al. (sedation efficiency score of $73 \%$ for $3-4$ year olds and $92 \%$ for 7 year olds and over (Lenahan et al. 2015)). In a contradictory study, Day et al. showed a reverse success rate, with $91 \%$ among the youngest compared with $65 \%$ of the oldest. This latter result is probably linked to a doubling of the dosage between the two groups (Day et al. 2006).

The increasing VCARS score according to the operator's experience can be easily explained by the learning context of a University Hospital. The senior practitioners (professors) become involved during the treatment when the VCARS score of the child dramatically increases.

\section{Alternative or complementary solutions}

To improve and optimize the treatment of our young patients, it is necessary to consider a complementary, non-pharmacological approach before the use of another drug, nitrous oxide or even general anesthesia. Indeed, a comparison between the use of hypnosis and midazolam in children undergoing outpatient surgery under

\section{Accepted manuscript}


general anesthesia showed a lower level of anxiety, better acceptance of the inhalation induction, fewer post-operative behavior disorders and a better experience in the hypnosis group (Calipel et al. 2005). The tell show do is already implemented during the first consultation, but there are other lines of thought to promote a soothing and reassuring atmosphere. It is also possible to act as soon as the child arrives because the waiting room environment decreases pre-operative anxiety (Fux-Noy et al. 2019). The presence of parents also reduces anxiety for the first visit, although in some cases they may be a source of stress (McNeil et al. 2019). Two literature reviews concluded that distraction techniques are effective with a low level of evidence (Goettems et al. 2017; Robertson et al. 2019). Listening to music during treatment had contradictory results in reducing anxiety and pain (Gupta et al. 2017; Navit et al. 2015; Singh et al. 2014). The use of a virtual reality headset that inhibits anxiety-provoking visual stimuli in the dental office also showed its effectiveness (Koticha et al. 2019).

Finally, Mejàre et al. encourages the conduct of primary clinical studies in order to obtain new recommendations and the generation of high quality evidence, as it has been done for the role of fluoride in the prevention of carious disease (Mejàre et al. 2015).

This professional practice evaluation has several biases in its performance. First, the hospital selection of patients is often referred by private practitioners for reasons of excessive stress, traumatic experience or failure to treatment. In addition, there is an inter-operator bias due to the multiplication of participants (5th or 6th grade students and senior) with different levels of expertise and experience. Indeed, verbal, nonverbal and body communications are not calibrated, and these would be avenues to consider in future evaluations. Finally, the adverse effects were only reported during the dental procedure and thus, future studies should include a follow up through the next 24 hours.

\section{Accepted manuscript}




\section{CONCLUSIONS}

- Conscious sedation with hydroxyzine following the maximum dosage recommendation for monotherapy is a good alternative for anxiety management during dental treatment.

- Almost 8 out of 10 paediatric patients at the Dental Care Centre of the University Hospital in Rennes benefited from a successful planned treatment.

- The results based on 184 paediatric patients were comparable to those found in the literature but without any noticeable adverse effects during the sessions. Extractions and restorative treatments in the oldest children (6 years and over) were also easier to perform.

- Behavior was predictive of the therapeutic outcome, since compliance to the prescription and low VCARS score before the procedure advance the treatment success. 


\section{REFERENCES}

Ashley PF, Chaudhary M, Lourenço-Matharu L. Sedation of children undergoing dental treatment. Cochrane Database Syst. Rev. 2018 17;12:CD003877.

Baygin $\mathrm{O}$, Bodur $\mathrm{H}$, Isik B. Effectiveness of premedication agents administered prior to nitrous oxide/oxygen. Eur. J. Anaesthesiol. 2010 Apr;27(4):341-6.

Calipel S, Lucas-Polomeni M-M, Wodey E, Ecoffey C. Premedication in children: hypnosis versus midazolam. Pediatr. Anesth. 2005;15(4):275-81.

Cianetti S, Lombardo G, Lupatelli E, Pagano S, Abraha I, Montedori A, et al. Dental fear/anxiety among children and adolescents. A systematic review. Eur. J. Paediatr. Dent. 2017 Jun;18(2):121-30.

Clough S, Shehabi Z, Morgan C. Medical risk assessment in dentistry: use of the American Society of Anesthesiologists Physical Status Classification. Br. Dent. J. 2016 Feb 12;220(3):103-8.

Coté CJ, Karl HW, Notterman DA, Weinberg JA, McCloskey C. Adverse Sedation Events in Pediatrics: Analysis of Medications Used for Sedation. Pediatrics. 2000 Oct 1;106(4):633-44.

Day PF, Power AM, Bibbert SA, Paterson SA. Effectiveness of Oral Midazolam for Paediatric Dental Care: A retrospective study in two Specialist Centres. Eur. Arch. Paediatr. Dent. 2006 Dec 1;7(4):228-35.

DeWitt P. qwraps2:Quick Wraps.R package version 0.4.2. [Internet]. 2019. Available from: https://CRAN.R-project.org/package=qwraps2

Fux-Noy A, Zohar M, Herzog K, Shmueli A, Halperson E, Moskovitz M, et al. The effect of the waiting room's environment on level of anxiety experienced by children prior to dental treatment: a case control study. BMC Oral Health. 2019 Dec 30;19(1):294.

Ghajari MF, Ansari G, Hasanbeygi L, Shayeghi S. Conscious Sedation Efficacy of 0.3 and $0.5 \mathrm{mg} / \mathrm{kg}$ Oral Midazolam for Three to Six Year-Old Uncooperative Children Undergoing Dental Treatment: A Clinical Trial. J. Dent. Tehran Iran. 2016 Mar;13(2):101-7.

Goettems ML, Zborowski EJ, Costa FDS, Costa VPP, Torriani DD. Nonpharmacologic Intervention on the Prevention of Pain and Anxiety During Pediatric Dental Care: A Systematic Review. Acad. Pediatr. 2017;17(2):110-9.

Gupta N, Gupta H, Gupta P, Gupta N. Evaluation of the Role of Music as a Nonpharmacological Technique in Management of Child Patients. J. Contemp. Dent. Pract. 2017 Mar 1;18(3):194-7.

Huang A, Tanbonliong T. Oral Sedation Postdischarge Adverse Events in Pediatric Dental Patients. Anesth. Prog. 2015;62(3):91-9.

\section{Accepted manuscript}


Klingberg G, Broberg AG. Dental fear/anxiety and dental behaviour management problems in children and adolescents: a review of prevalence and concomitant psychological factors. Int. J. Paediatr. Dent. 2007 Nov;17(6):391-406.

Koticha P, Katge F, Shetty S, Patil DP. Effectiveness of Virtual Reality Eyeglasses as a Distraction Aid to Reduce Anxiety among 6-10-year-old Children Undergoing Dental Extraction Procedure. Int. J. Clin. Pediatr. Dent. 2019 Aug;12(4):297-302.

Lahoud GY, Averley PA. Comparison of sevoflurane and nitrous oxide mixture with nitrous oxide alone for inhalation conscious sedation in children having dental treatment: a randomised controlled trial. Anaesthesia. 2002;57(5):446-50.

Lam C, Udin RD, Malamed SF, Good DL, Forrest JL. Midazolam Premedication in Children: A Pilot Study Comparing Intramuscular and Intranasal Administration. Anesth. Prog. 2005;52(2):56-61.

Lane KJ, Nelson TM, Thikkurissy S, Scott JM. Assessing Temperament as a Predictor of Oral Sedation Success Using the Children's Behavior Questionnaire Short Form. Pediatr. Dent. 2015 Oct;37(5):429-35.

Lenahan M, Wells M, Scarbecz M. A Retrospective Study of 248 Pediatric Oral Sedations Utilizing the Combination of Meperidine and Hydroxyzine for Dental Treatment. J. Clin. Pediatr. Dent. 2015;39(5):481-7.

Marek H. stargazer: Well-Formatted Regression and Summary Statistics Tables. R package version 5.2.1. [Internet]. 2018. Available from: https://CRAN.Rproject.org/package=stargazer

McNeil DW, Randall CL, Cohen LL, Crout RJ, Weyant RJ, Neiswanger K, et al. Transmission of dental fear from parent to adolescent in an Appalachian sample in the USA. Int. J. Paediatr. Dent. 2019;29(6):720-7.

Mejàre IA, Klingberg G, Mowafi FK, Stecksén-Blicks C, Twetman SHA, Tranæus SH. A Systematic Map of Systematic Reviews in Pediatric Dentistry-What Do We Really Know? PLOS ONE. 2015 Feb 23;10(2):e0117537.

Motola D, Donati M, Biagi C, Calamelli E, Cipriani F, Melis M, et al. Safety profile of $\mathrm{H} 1$-antihistamines in pediatrics: an analysis based on data from VigiBase. Pharmacoepidemiol. Drug Saf. 2017;26(10):1164-71.

Navit S, Johri N, Khan SA, Singh RK, Chadha D, Navit P, et al. Effectiveness and Comparison of Various Audio Distraction Aids in Management of Anxious Dental Paediatric Patients. J. Clin. Diagn. Res. JCDR. 2015 Dec;9(12):ZC05-9.

Nelson TM, Griffith TM, Lane KJ, Thikkurissy S, Scott JM. Temperament as a Predictor of Nitrous Oxide Inhalation Sedation Success. Anesth. Prog. 2017;64(1):17-21.

Olasińska-Wiśniewska A, Olasiński J, Grajek S. Cardiovascular safety of antihistamines. Postepy Dermatol. Alergol. 2014 Jun;31(3):182-6.

\section{Accepted manuscript}


Pediatrics AA of, Dentistry AA of P, Coté CJ, Wilson S. Guidelines for Monitoring and Management of Pediatric Patients During and After Sedation for Diagnostic and Therapeutic Procedures: An Update. Pediatrics. 2006 Dec 1;118(6):2587-602.

Prescribers' digital reference. Hydroxyzine Hydrochloride Syrup (hydroxyzine hydrochloride) dose, indications, adverse effects, interactions... from PDR.net [Internet]. 2020 [cited 2020 Jun 12]. Available from: https://www.pdr.net/drugsummary/Hydroxyzine-Hydrochloride-Syrup-hydroxyzine-hydrochloride-740

R Core Team. A language and environment for statistical computing [Internet]. 2018. Available from: https://www.R-project.org

al-Rakaf H, Bello LL, Turkustani A, Adenubi JO. Intra-nasal midazolam in conscious sedation of young paediatric dental patients. Int. J. Paediatr. Dent. 2001 Jan;11(1):33-40.

Ritwik P, Cao LT, Curran R, Musselman RJ. Post-sedation Events in Children Sedated for Dental Care. Anesth. Prog. 2013;60(2):54-9.

Robertson M, Araujo M, Innes N. Anxiety and fear management in paediatric dentistry using distraction techniques. Evid. Based Dent. 2019 Jun;20(2):50-1.

Sado-Filho J, Viana KA, Corrêa-Faria P, Costa LR, Costa PS. Randomized clinical trial on the efficacy of intranasal or oral ketamine-midazolam combinations compared to oral midazolam for outpatient pediatric sedation. PLoS ONE [Internet]. 2019 Mar 11 [cited 2020 Mar 2];14(3). Available from: https://www.ncbi.nlm.nih.gov/pmc/articles/PMC6411109/

Schlit A-F, Delaunois A, Colomar A, Claudio B, Cariolato L, Boev R, et al. Risk of QT prolongation and torsade de pointes associated with exposure to hydroxyzine: reevaluation of an established drug. Pharmacol. Res. Perspect. 2017;5(3):e00309.

Shapira J, Kupietzky A, Kadari A, Fuks AB, Holan G. Comparison of Oral Midazolam With and Without Hydroxyzine in the Sedation of Pediatric Dental Patients [Internet]. 2004 [cited 2019 Aug 2]. Available from: https://www.ingentaconnect.com/content/aapd/pd/2004/00000026/00000006/art0000 4

Singh D, Samadi F, Jaiswal J, Tripathi AM. Stress Reduction through Audio Distraction in Anxious Pediatric Dental Patients: An Adjunctive Clinical Study. Int. J. Clin. Pediatr. Dent. 2014;7(3):149-52.

Smith SJ. Cardiovascular toxicity of antihistamines. Otolaryngol.--Head Neck Surg. Off. J. Am. Acad. Otolaryngol.-Head Neck Surg. 1994 Sep;111(3 Pt 2):348-54.

Somri M, Parisinos CA, Kharouba J, Cherni N, Smidt A, Abu Ras Z, et al. Optimising the dose of oral midazolam sedation for dental procedures in children: a prospective, randomised, and controlled study: Optimal oral midazolam dose in sedation of paediatric dentistry. Int. J. Paediatr. Dent. 2012 Jul;22(4):271-9.

\section{Accepted manuscript}


Torres-Pérez J, Tapia-García I, Rosales-Berber MA, Hernández-Sierra JF, PozosGuillén A de J. Comparison of three conscious sedation regimens for pediatric dental patients. J. Clin. Pediatr. Dent. 2007;31(3):183-6.

Venham LL, Gaulin-Kremer E, Munster E, Bengston-Audia D, Cohan J. Interval rating scales for children's dental anxiety and uncooperative behavior. Pediatr. Dent. 1980 Sep;2(3):195-202.

Vishwakarma AP, Bondarde PA, Patil SB, Dodamani AS, Vishwakarma PY, Mujawar $\mathrm{SA}$. Effectiveness of two different behavioral modification techniques among 5-7year-old children: A randomized controlled trial. J. Indian Soc. Pedod. Prev. Dent. 2017 Jun;35(2):143-9.

Wickham H. ggplot2: Elegant Graphics for Data Analysis. Springer-Verlag New York; 2016.

Wong AR, Rasool AHG. Hydroxyzine-Induced Supraventricular Tachycardia in a Nine-year-old Child. 2004;3. 


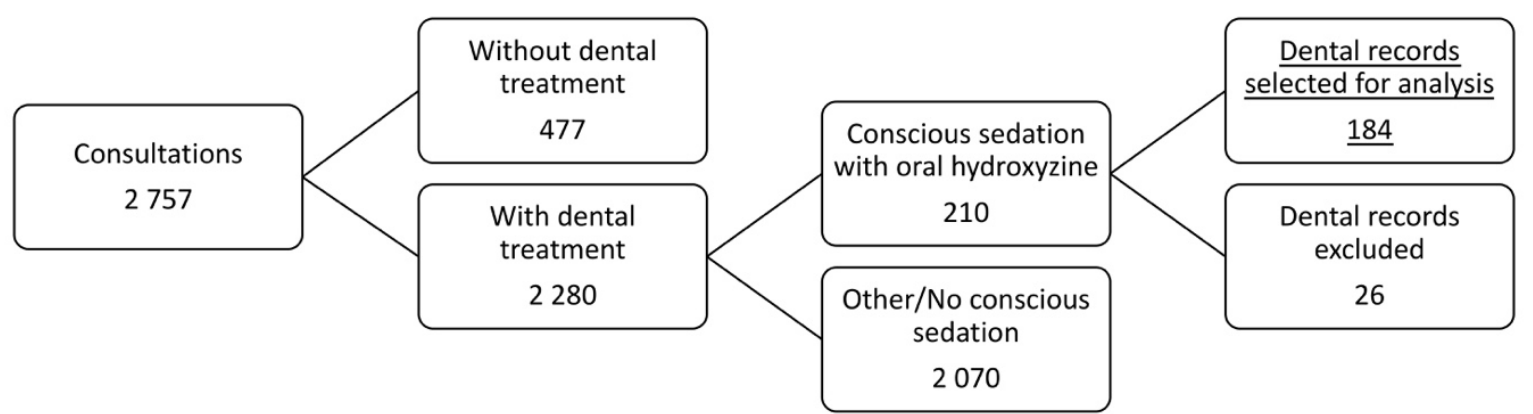

Figure 1: Flow chart for the selection of dental records analysed in the study. 
Table 1: Characteristics of patients, oral hydroxyzine prescription and compliance in the general population and according to the therapeutic outcome during the second visit with treatment.

\begin{tabular}{|c|c|c|c|c|}
\hline & $(n=184)$ & $\begin{array}{l}\text { Success } \\
(n=144)\end{array}$ & $\begin{array}{l}\text { Failure } \\
(n=40)\end{array}$ & $\begin{array}{c}p- \\
\text { value }\end{array}$ \\
\hline Age (years) & $6.80 \pm 2.23$ & $6.94 \pm 2.33$ & $6.32 \pm 1.76$ & $0.118^{a}$ \\
\hline \multicolumn{5}{|l|}{ Gender } \\
\hline Male & $104(56.5 \%)$ & $82(56.9 \%)$ & $22(55.0 \%)$ & $0.826^{b}$ \\
\hline Female & $80(43.5 \%)$ & $62(43.1 \%)$ & $18(45.0 \%)$ & \\
\hline Weight (kg) & $22.92 \pm 7.64$ & $23.24 \pm 8.03$ & $21.75 \pm 5.94$ & $0.395^{a}$ \\
\hline $\begin{array}{l}\text { Prescription (mg } \\
\text { hydroxyzine/kg) }\end{array}$ & $1.63 \pm 0.39$ & $1.61 \pm 0.39$ & $1.67 \pm 0.38$ & $0.302^{a}$ \\
\hline \multicolumn{5}{|l|}{ Compliance to medication } \\
\hline Yes & $158(85.9 \%)$ & $129(89.6 \%)$ & $29(72.5 \%)$ & $0.010^{c}$ \\
\hline No & $26(14.1 \%)$ & 15 (10.4\%) & $11(27.5 \%)$ & \\
\hline $\begin{array}{l}\text { Interval between drug intake } \\
\text { and dental treatment (min) }\end{array}$ & $89.96 \pm 26.01$ & $90.29 \pm 27.23$ & $88.75 \pm 21.27$ & $0.966^{a}$ \\
\hline \multicolumn{5}{|l|}{ First use of hydroxyzine } \\
\hline Yes & $86(46.7 \%)$ & $67(46.5 \%)$ & $19(47.5 \%)$ & $0.913^{b}$ \\
\hline No & 98 (53.3\%) & 77 (53.5\%) & $21(52.5 \%)$ & \\
\hline
\end{tabular}

Bold $p$-values are statistically significant at: $p<0.05$.

aMann-Whitney, ${ }^{b} \times 2$, 'Fisher tests; statistically significant at: $p<0.05$.

\section{Accepted manuscript}


Table 2: Description of patient's behavior and dental treatment parameters, in the general population and according to the therapeutic outcome during the second visit with treatment.

\begin{tabular}{|c|c|c|c|c|}
\hline & $(n=184)$ & $\begin{array}{l}\text { Success } \\
(n=144)\end{array}$ & $\begin{array}{l}\text { Failure } \\
(n=40)\end{array}$ & $p$-value \\
\hline $\begin{array}{l}\text { VCARS score before } \\
\text { procedure }\end{array}$ & $0.85 \pm 1.14$ & $0.67 \pm 0.94$ & $1.52 \pm 1.50$ & $<0.001^{\mathrm{a}}$ \\
\hline $\begin{array}{l}\text { VCARS score during } \\
\text { procedure }\end{array}$ & $1.88 \pm 1.75$ & $1.36 \pm 1.42$ & $3.75 \pm 1.51$ & $<0.001^{a}$ \\
\hline $\begin{array}{l}\text { VCARS score after } \\
\text { procedure }\end{array}$ & $0.89 \pm 1.24$ & $0.63 \pm 0.95$ & $1.82 \pm 1.65$ & $<0.001^{a}$ \\
\hline \multicolumn{5}{|l|}{ Dental treatment } \\
\hline Restorative & $96(54.5 \%)$ & $80(55.6 \%)$ & $16(40.0 \%)$ & $0.028^{c}$ \\
\hline Endodontic & $16(9.1 \%)$ & $9(6.2 \%)$ & $7(17.5 \%)$ & \\
\hline Extraction & $64(36.4 \%)$ & $55(38.2 \%)$ & $9(22.5 \%)$ & \\
\hline \multicolumn{5}{|l|}{ Successful anesthesia } \\
\hline Yes & $136(73.9 \%)$ & $116(80.6 \%)$ & $20(50.0 \%)$ & $<0.001^{b}$ \\
\hline No & $48(26.1 \%)$ & $28(19.4 \%)$ & $20(50.0 \%)$ & \\
\hline \multicolumn{5}{|l|}{ Injection technique } \\
\hline Infiltration & $60(44.1 \%)$ & $55(47.4 \%)$ & $5(12.5 \%)$ & $0.062^{b}$ \\
\hline Intraosseous & $76(55.9 \%)$ & $61(52.6 \%)$ & $15(37.5 \%)$ & \\
\hline \multicolumn{5}{|l|}{ Operator } \\
\hline 5 th grade student & $125(67.9 \%)$ & $100(69.4 \%)$ & $25(62.5 \%)$ & $0.654^{b}$ \\
\hline 6 th grade student & $30(16.3 \%)$ & $23(16.0 \%)$ & $7(17.5 \%)$ & \\
\hline Senior & $29(15.8 \%)$ & $21(14.6 \%)$ & $8(20.0 \%)$ & \\
\hline \multicolumn{5}{|l|}{ Time slot } \\
\hline Early morning & $43(23.4 \%)$ & $33(22.9 \%)$ & $10(25.0 \%)$ & $0.895^{\mathrm{b}}$ \\
\hline Late morning & $47(25.5 \%)$ & $38(26.4 \%)$ & $9(22.5 \%)$ & \\
\hline Early afternoon & $53(28.8 \%)$ & $40(27.8 \%)$ & $13(32.5 \%)$ & \\
\hline Late afternoon & $41(22.3 \%)$ & $33(22.9 \%)$ & $8(20.0 \%)$ & \\
\hline
\end{tabular}

Bold $p$-values are statistically significant at: $p<0.05$.

${ }^{\mathrm{a}}$ Mann-Whitney, ${ }^{\mathrm{b}} \mathrm{X} 2,{ }^{\mathrm{c}}$ Fisher tests.

VCARS: Vehnam's Clinical Anxiety Rating Scale.

\section{Accepted manuscript}


Table 3: Regression models with parameters related to patient, oral hydroxyzine prescription and dental treatment as explanatory variables for the patient's anxiety during the dental procedure, and for the therapeutic success.

\begin{tabular}{|c|c|c|}
\hline & \multicolumn{2}{|c|}{ Dependent variables: } \\
\hline & $\begin{array}{l}\text { VCARS score during } \\
\text { procedure } \\
\text { Multiple linear regression }\end{array}$ & $\begin{array}{l}\text { Therapeutic } \\
\text { success } \\
\text { Logistic regression }\end{array}$ \\
\hline Prescription of hydroxyzine & $-0.033(0.355)$ & $-1.175(0.938)$ \\
\hline $\begin{array}{l}\text { Interval between drug intake and } \\
\text { dental treatment }\end{array}$ & $0.003(0.005)$ & $0.013(0.017)$ \\
\hline Compliance to medication: No & $0.858^{*}(0.389)$ & $-1.837^{*}(0.770)$ \\
\hline Gender: Female & $-0.012(0.260)$ & $-0.224(0.633)$ \\
\hline Age & $-0.075(0.060)$ & $0.078(0.184)$ \\
\hline First use of hydroxyzine: No & $-0.063(0.265)$ & $-0.691(0.687)$ \\
\hline Dental treatment: Endodontic & $0.429(0.443)$ & $-2.638^{\star \star}(0.874)$ \\
\hline Dental treatment: Extraction & $0.217(0.296)$ & $-0.841(0.761)$ \\
\hline VCARS score before procedure & $0.664^{\star \star \star *}(0.131)$ & $-0.735^{\star \star}(0.255)$ \\
\hline Time slot: late morning & $0.347(0.388)$ & $-1.519(0.963)$ \\
\hline Time slot: early afternoon & $0.620(0.374)$ & $-0.642(0.905)$ \\
\hline Time slot: late afternoon & $0.163(0.409)$ & $-0.282(0.995)$ \\
\hline Injection technique: Intraosseous & $0.153(0.287)$ & $-1.375(0.709)$ \\
\hline Operator: $6^{\text {th }}$ grade student & $0.206(0.355)$ & $-0.194(0.850)$ \\
\hline Operator: Senior & $1.395^{\star *}(0.423)$ & $1.585(0.998)$ \\
\hline Observations & 136 & 136 \\
\hline R2 & 0.387 & \\
\hline Adjusted R2 & 0.310 & \\
\hline Log Likelihood & & -40.891 \\
\hline Akaike Inf. Crit. & & 113.782 \\
\hline Residual Std. Error & $1.450(\mathrm{df}=120)$ & \\
\hline F Statistic & $\mathbf{5 . 0 4 8}^{\star * * *}(\mathrm{df}=15 ; 120)$ & \\
\hline
\end{tabular}

\section{Accepted manuscript}


Table 4: Summary of the previously published sedation protocols used in pediatric dentistry.

\begin{tabular}{|c|c|c|c|c|c|c|c|c|}
\hline Journal & Years & $\mathbf{n}$ & $\begin{array}{c}\text { Age } \\
\text { (year) }\end{array}$ & Evaluation & Methods and sedation type & $\begin{array}{c}\text { Success } \\
\text { rate }^{\mathrm{a}}\end{array}$ & Side effects & Reference \\
\hline \multicolumn{9}{|c|}{ Hydroxyzine as monotherapy } \\
\hline $\begin{array}{c}\text { Journal of } \\
\text { pediatric dentistry }\end{array}$ & 2007 & 18 & $1-10$ & $\begin{array}{l}\text { - Ohio state behavior rating } \\
\text { scale } \\
\text { - Heart rate } \\
-\mathrm{O}_{2} \text { saturation }\end{array}$ & $\begin{array}{l}\text { Hydroxyzine } \\
2 \mathrm{mg} \cdot \mathrm{Kg}^{-1} 2 \mathrm{~h} \text { before } \\
+1 \mathrm{mg} \cdot \mathrm{Kg}^{-1} 20 \mathrm{~min} \text { before }\end{array}$ & $100 \%$ & $-b$ & $\begin{array}{l}\text { (Torres- } \\
\text { Pérez et al. } \\
2007 \text { ) }\end{array}$ \\
\hline
\end{tabular}

Midazolam as monotherapy

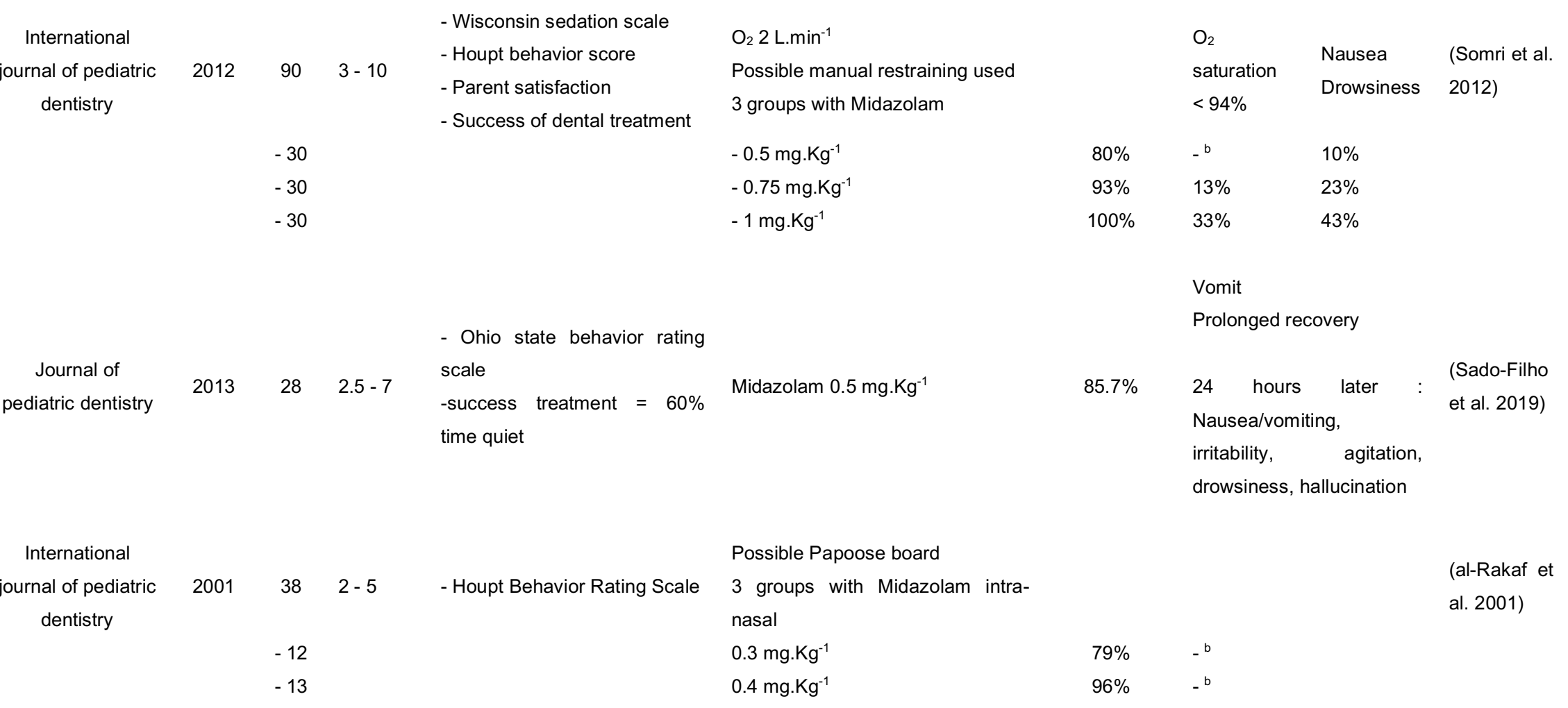

\section{Accepted manuscript}


European

Archives of

Paediatric

2006

$101 \quad 1-11$

- Success of dental treatment

Two dental clinics

Midazolam

(Day et al.

2006)

Dentistry

$-44 \quad 2.9 \pm 1.6$

$-57 \quad 5.0 \pm 1.9$

$0.5-0.7 \mathrm{mg} \cdot \mathrm{Kg}^{-1}$

$0.2-0.3 \mathrm{mg} \cdot \mathrm{Kg}^{-1}$

Internet streaming video

$\mathrm{N}_{2} \mathrm{O} 50 \%$

$85 \%$

Anesthesia
progress

2017

$48 \quad 3-8$

Behavior score

- Frankl score

\section{- VCARS}

- Level of consciousness

$\mathrm{N}_{2} \mathrm{O} 40 \%$

$52 \%$

- Ramsay Sedation Score

European journal

of anaesthesiology

2010

15

$5-8$

- Bis

$\mathrm{N}_{2} \mathrm{O} 40 \%$

- Frankl behavior rating score

- Ohio state behavior rating

scale

- Cardiac Frequency

- $\mathrm{O}_{2}$ saturation

Midazolam $0.5 \mathrm{mg} . \mathrm{Kg}^{-1}$

+ Hydroxyzine $1.5 \mathrm{mg}^{\mathrm{Kg}}{ }^{-1}$

Chloral $50 \mathrm{mg}^{\mathrm{Kg}}$

+ Hydroxyzine $1.5 \mathrm{mg} . \mathrm{Kg}$
(Torres-

Pérez et al.

2007)

\section{Accepted manuscript}


Midazolam $0.5 \mathrm{mg} \mathrm{Kg}^{-1}$ per os

+ Kétamine $3 \mathrm{mg} \cdot \mathrm{Kg}^{-1}$

\section{$\mathrm{N}_{2} \mathrm{O} 40 \%$}

+ Sevoflurane 0.1 to $0.3 \%$

- Level of consciousness

Houpt Behavior Rating Scale

Dentistry of

Tehran

\begin{tabular}{|c|c|c|c|c|}
\hline & & & & - temperament scale \\
\hline Pediatric dentistry & 2015 & 61 & $3-8$ & - Houpt Behavior Rating Scale \\
\hline
\end{tabular}

The Journal of

Clinical Pediatric

Dentistry
2015
- Behavior during the dental

treatment

- Frankl score

- Sedation score
Mépéridine $2.2 \mathrm{mg} \cdot \mathrm{Kg}^{-1}$

+ Hydroxyzine 1 to $2 \mathrm{mg} \cdot \mathrm{Kg}^{-1}$
Midazolam $0.3 \mathrm{mg} \cdot \mathrm{Kg}^{-1}$

+ Hydroxyzine $1 \mathrm{mg} \cdot \mathrm{Kg}^{-1}$

Midazolam 0.5 mg. $\mathrm{Kg}^{-1}$

+ Hydroxyzine $1 \mathrm{mg} \cdot \mathrm{Kg}^{-1}$

Midazolam $0.3 \mathrm{mg} . \mathrm{Kg}^{-1}$

+ Hydroxyzine $1 \mathrm{mg} \cdot \mathrm{Kg}^{-1}$

+ Mépéridine $1.5 \mathrm{mg} \cdot \mathrm{Kg}^{-1}$

$+\mathrm{N}_{2} \mathrm{O} 50 \%$

+ Internet streaming video

$87 \% \quad N C$

81.5\% Nausea/vomiting

$\mathrm{O}_{2}$ saturation $<90 \%$

(Lenahan et

al. 2015)
(Lahoud

and Averley

2002)

(Ghajari et

al. 2016)

(Lane et al.

2015)

\section{Accepted manuscript}


European journal
of anaesthesiology

2010

45

$5-8$

Ramsay Sedation Score

- Bis

- Frankl behavior rating score

$-15$

$-15$

$-15$

Anesthesia

progress

- Houpt Behavior Rating Scale
Hydroxyzine $1 \mathrm{mg} \cdot \mathrm{Kg}^{-1}$

$$
+\mathrm{N}_{2} \mathrm{O} 40 \%
$$

Midazolam $0.7 \mathrm{mg} \mathrm{Kg}^{-1}$

$+\mathrm{N}_{2} \mathrm{O} 40 \%$

Kétamine $3 \mathrm{mg} \cdot \mathrm{Kg}^{-1}$

+ midazolam $0.25 \mathrm{mg} \cdot \mathrm{Kg}^{-1}$

$+\mathrm{N}_{2} \mathrm{O} 40 \%$

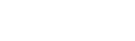

Midazolam $0.2 \quad \mathrm{mg}_{\mathrm{Kg}}{ }^{-1}$
intramuscular
$+\mathrm{N}_{2} \mathrm{O} 50 \%$
Midazolam $0.2 \mathrm{mg} \cdot \mathrm{Kg}^{-1}$ intranasal
$+\mathrm{N}_{2} \mathrm{O} 50 \%$

$66 \%$

$74 \% \quad$ Nausea, cough, hiccough, enuresia, bronchospasm

Nausea, hypersalivation, hallucination
(Lam et al.

2005)
Before full anesthesia, comparison of 2 groups :

- Hypnosis

- Midazolam $0.2 \mathrm{mg} \cdot \mathrm{Kg}^{-1}$
When hypnosis is used

- less Anxiety during induction

- less behavior trouble $48 \mathrm{~h}$ al. 2005)

(Calipel

post-operative

NC: non communicated; ${ }^{\text {a: }}$ sedation or therapeutic success rate, as reported by the authors; ${ }^{\text {b }}$ no adverse effects reported. VCARS: Venham's clinical anxiety rating scale; Bis:

bisprectral index score; MYPAS: Modified Yale Preoperative Anxiety Scale; PHBQ: Post-hospitalization Behavioral Questionnaire

\section{Accepted manuscript}


Supplementary Table 1: Description of patient's characteristics, compliance and behavior, oral hydroxyzine prescription, and dental treatment according to the age.

$\begin{array}{ll}\text { Age: } 3 \text { to } 5 & \text { Age: } 6 \text { and older } p \text {-value } \\ (n=43) & (n=105)\end{array}$

Gender

Male

Female

Dosage (mg hydroxyzine/kg)

Compliance to medication

Yes

Delay drug intake - dental treatment (min)

First use of hydroxyzine

Yes

No

VCARS score before procedure

VCARS score during procedure

VCARS score after procedure

Dental treatment

Restorative

Endodontic

Extraction

Successful anaesthesia

Yes

No

Injection technique

Infiltration

Intra-osseous

Operator

$5^{\text {th }}$ grade student

$6^{\text {th }}$ grade student

Senior

\section{Time slot}

Early morning
Late morning
Early afternoon
Late afternoon

Therapeutic success

Yes

No
$23(53.5 \%)$

$20(46.5 \%)$

$1.67 \pm 0.39$

$35(81.4 \%)$

$8(18.6 \%)$

$88.14 \pm 23.12$

$24(55.8 \%)$

19 (44.2\%)

$1.14 \pm 1.49$

$2.51 \pm 1.98$

$1.14 \pm 1.49$

$24(55.8 \%)$

$5(11.6 \%)$

$12(27.9 \%)$

$30(69.8 \%)$

$13(30.2 \%)$

11 (25.6\%)

19 (44.2\%)

$22(51.2 \%)$

11 (25.6\%)

$10(23.3 \%)$

15 (34.9\%)

$13(30.2 \%)$

11 (25.6\%)

4 (9.3\%)

$28(65.1 \%)$

15 (34.9\%)
67 (63.8\%)

$0.243^{b}$

38 (36.2\%)

$1.59 \pm 0.40$

$0.081^{a}$

$92(87.6 \%)$

$0.325^{b}$

$13(12.4 \%)$

$92.02 \pm 28.45$

$0.997^{a}$

$50(47.6 \%)$

$0.365^{b}$

55 (52.4\%)

$0.74 \pm 0.91$

$0.282^{a}$

$1.68 \pm 1.60$

$0.020^{\mathrm{a}}$

$0.77 \pm 1.04$

$0.256^{\mathrm{a}}$

$52(49.5 \%)$

$0.236^{b}$

$6(5.7 \%)$

$42(40.0 \%)$

79 (75.2\%)

$0.493^{b}$

$26(24.8 \%)$

39 (37.1\%)

$0.235^{\mathrm{b}}$

$40(38.1 \%)$

$81(77.1 \%)$

$0.007^{b}$

$11(10.5 \%)$

$13(12.4 \%)$

$20(19 \%)$

$0.020^{b}$

$22(21.0 \%)$

$32(30.5 \%)$

31 (29.5\%)

$85(81.0 \%)$

$0.040^{b}$

\footnotetext{
${ }^{\mathrm{a}}$ Mann-Whitney, ${ }^{\mathrm{b}} \mathrm{X} 2$ tests; statistically significant at: $p<0.05$.
}

\section{Accepted manuscript}

